\title{
Social disconnectedness among widows in Nigeria: probing the effects of self-monitoring intervention
}

\author{
Victor Moses $\odot$ \\ Department of Educational Psychology and Couselling, Ahmadu Bello University, Zaria, Nigeria
}

DOI: 10.18621 /eurj.430761

\begin{abstract}
Objectives: There could be no group more affected by social disconnectedness than widows and many who suffer from social disconnectedness live a lonely life, suffer depression, anxiety, low self-esteem and selfworth, and are hunted by the constant thought of suicide. Developing an intervention to provide reprieve may help widows take back their lives. This article therefore, presents the results of a study probing the effectiveness of self-monitoring intervention in reducing social disconnectedness among the widows in Kaduna state, Nigeria. Methods: The study used the quasi-experimental method involving pretest and posttest. The data were collected using Social Disconnectedness Questionnaire from 47 widows in the treatment group and 45 widows in the waitlist control group. The mean age of the participants $(42.33 \pm 6.38$ years [95\%CI $=41.02-43.63]$, range; 28.0-56.0 years).

Results: Analysis of the data suggests that self-monitoring intervention is significantly effective in reducing social disconnectedness behaviour problem among the widows in the study area. After eight weeks of selfmonitoring intrevention, social disconnectedness behaviour among the widows reduced by $39 \%$ compared to $5.63 \%$ observed in the waitlist control group.

Conclusions: The outcome adds to the literature as one of few studies investigating self-monitoring intervention among widows and calls for increased probing to establish the efficacy of self-monitoring in reducing social disconnectedness in widows in Nigeria and elsewhere in the world.
\end{abstract}

Keywords: Social disconnectedness, widows, self-monitoring intervention

Received: June 5, 2018; Accepted: August 2, 2018; Published Online: September 19, 2018

$\mathrm{T}$ he state of having lost one's spouse to death is becoming prevalent in the present worldbecause of natural or man-made disaster and thus, rendering lots of women into Widowhood. There are an estimated 258 million widows across the world, and more than 115 million live in poverty, 86 million have suffered physical abuse and 1.5 million children whose mothers who have been widowed will die before reaching the age of five [1]. Usually, with the death of a husband, the world of a woman falls apart and she has to dwell in a cruel world, full of misery and shame and abuses for the rest of her life. There is no group more affected by the sin of omission than widows. They are painfully absent from the statistics of many developing countries, and they are rarely mentioned in the multitude of reports on women's poverty, development, health or human rights published in the last twenty-five years [2]. Their plight is one of the most important, yet under-reported issues facing the world today. For many women, however, becoming a widow 
does not just mean the heartache of losing a husband, but often losing everything else as well. In too many countries, a woman who is widowed becomes in effect a non-person. Through no fault of her own, she can suffer social discrimination, stigma and even violence, sometimes, as in parts of sub-Saharan Africa, being forced to "cleanse" herself by having sexual intercourse with a relative or a stranger. A widow may also be denied inheritance and land rights or forced to drink the water that was used to clean her dead husband's body. Although, much has been made, and rightly so, of gender inequality, but widows have truly been at the bottom of the pile - invisible and unheard - for too long. These sufferings could lead to serious mental and physical health problems. While some emotional reactions can hardly be avoided following the loss of a loved one, a key question is how can the society protect the bereaved from unduly long-lasting and/or extreme consequences?

Most bereaved people suffer from loneliness, isolation or social disconnectedness. This is a situation characterized by behavioral, social, or emotional problem. Although, some individuals appear content to spend most of their hours and days removed from others, there are individuals who have little choice in the matter of solitude because they are isolated or rejected by others in their social communities and or having feeling of worthless and therefore decide to live alone. Vasa and Pine [3] believe that social disconnectedness is linked to psychological maladaptation as it represents a behavioral expression of internalized thoughts and feelings of social anxiety or depression.In the cases of the avoidance of social company and the disconnection from social company, solitude could hardly be construed as psychologically or socially adaptive. It is not the display of solitude per se that may pose a problem; rather, the central issue is that social disconnectedness may reflect underlying difficulties of a social or emotional nature.

The term "social disconnectedness" is not a diagnosis for a specific psychiatric disorder. Disconnectedness means both the phenomenon of social isolation and the pathology of introverted behaviour. The former refers to the condition of staying in one's own house to avoid relationships with others, including family members, the latter means pathology due to some psychiatric disorders or personality of introversion. Patients in isolation are classified into a "sec- ondary isolation group" due to psychiatric disorders, and a "primary isolation group" characterized by isolation itself [4]. It is also viewed as an individual's subjective experience of a lack of satisfying human relationships, usually accompanied with a negative feeling, causing distress to an individual. It is related to several characteristics that impair the quality of life of widows, like depressive symptoms and decreased subjective health. It may lead to cognitive decline, increased need of help and use of health services, as well as early institutionalization of the widows after the loss of the spouse [5-8].

Generally, socially disconnected people often experience a subjective sense of inner emptiness or hollowness, with feelings of separation or isolation from the world, and a woman grieving for the loss of her husband is not an exemption $[6,7]$. Sure, the loss of a spouse is a challenging and life changing experience, this is even worse among elderly and young married women. Whether the spouse dies expectedly or unexpectedly, socially withdrawn behaviour among the widows whose social network has already been reduced, affects the widows' quality of life and they become more vulnerable to loneliness. Although social support may buffer the effects of loneliness such as mental problems, depression, insomnia and hallucinations of the dead, widows arguably have lower levels of social support in Nigeria than married individuals do. Social disconnectedness has been identified as a risk factor for psychosocial maladjustment [9], and associated with such negative, interpersonaland intrapersonal difficulties as low self-esteem, negative self-perceptions of social competence, and anxiety [9, $10]$.

Research shows that widows who suffer from social isolation are hunted by the constant thought of suicide. They are emotionally down cast and as well view the future hopelessly and helplessly. This condition is even worse among widows with children to care for. Growing evidence of their vulnerability to isolation and loneliness, socioeconomic and psychological challenges in the society present a danger waiting to happen. In many developing countries, the exact numbers of widows, their ages and other social and economic aspects of their lives are unknown. However, almost worldwide, widows comprise a significant proportion of all women, ranging from 7 per cent to 16 per cent of all adult women [11]. It is a common knowledge 
that in African context, widows receive some of the worse of treatment, and endure the worst of ordeals, which makes them susceptible to lots of psychological distress.

In Nigeria as in many parts of the developing world, the exact number of widows is unknown if it is available, it will be a matter of gross estimates. Beside the ages of these women and much of their socio-economic conditions are poorly accounted for. Broadly stated, while widowhood is largely experienced by elderly women in the developed world, the reverse is the case in developing countries such as Nigeria where younger women, many of whom may still be bearing children are widows. With early marriages still largely in practice in Nigeria, many girls given out in marriage are turned widows before adulthood.

The phenomenon of widowhood is attributed to death of a husband which causes are varied. In contemporary societies like Nigeria, the first notable variety of death worth considering due to its profound and immediate impact on widowhood in terms of creating many widows at a given time is war or armed conflict. World War I and II, the Ibo pogroms of 1966, the violent political crisis in Western Nigeria in the mid-1960s, the Nigerian civil war of 1967-1970 all produced more widows than any period in modern Nigeria [12]. Ethnic and religious conflicts such as the Tiv riots of the 1960s; the Tiv-Jukun crises of the early 1990s and 2001; the Ife-Modakeke crisis of 2000, the Amuleri-Aguleri in South-Eastern Nigeria in 2001; the Maitatsine religious crisis of the 1980s that erupted in Kaduna and spread across northern Nigeria with flash points in states like Kano, Bauchi and Plateau; countless acts of suicide bombing, the recurring ethno-religious crises in Jos, Plateau State and Kaduna metropolis since 2000 have all combined to produce additional widows in huge numbers [13-16). In between these are unreported cases of violent conflicts between minority ethnic groups that result in male causalities. Since 1999, the Niger Delta crisis, electoral related violence and the Boko Haram menace in Maiduguri and Yobe and the Fulani herdsmen and Farmers crises have caused substantial deaths in Nigeria. The group has carried out heavy attacks since 2007 in Maiduguri, Kano, the Police Headquarters in Abuja, churches in Abuja and Suleija in Niger state and at the United Nations house in Abuja [17-20] and most recently, the killings of Reverend Fathers and worship- pers in Benue state.

Without debate, majority of those who lost their lives in all these wars and crises and bombings are men many of whom were married. Those left behind include widows and children in a sizeable proportion. Once upon the death of a husband, irrespective of the age of the wife, she descends into widowhood and depending on the cultural background of the marriage; the widow's conduct and activities are henceforth regulated by customary practices and norms. In general, according to Eweluka [21], widowhood rites include isolation and confinement, restrictions in movement and association and hair shaving.

Nigerian widows like their counterpart elsewhere in especially Africa and Asia are a special social category that is scantly acknowledged in social policy but is potently vulnerable to psychological, socioeconomic and health risks because of the widowhood practices prevalent in Nigeria. One of the major effects of widowhood is poverty and emotional trauma. Many Nigerian widows are pauperized by those. These practices drastically reduce the economic status of widows upon the death of a husband. It is difficult to achieve a good life by a widow when she has no right to inheritance. Upon the death of a husband, widows may be completely dispossessed and chased off [22]. Widowhood is simply a life of deprivation.

In Nigeria, women outlive their husbands, because they marry men older than themselves, that is why widows outnumber widowers and the average woman can expect to survive her husband. In fact, widows make up a substantial proportion of the elderly population. The pattern of grieving will repeat itself over and over again, month after month, and that all the unbearable feelings and fears, of being unable to function as a human being any more, are normal. During this period, fatigue, anxiety, lack of interest and reduced functioning are common. Social disconnectedness is the most radical life events one can experience and it can have far-reaching consequences for the mental wellbeing. In order to promote mental and general wellbeing and to alleviate loneliness and social disconnectedness among widows, intervention programs must be developed to improve existing or develop new relationships such as friendships [23-25].

Decades of research, using self-monitoring technique, a personality trait that refers to an ability to regulate behavior to accommodate social situations has 
proven to be an effective behavioral intervention used in modifying various behavior problems. Based on the effects of this behavior, this study was carried out to assess the extent to which self-monitoring technique can alleviate the effect of social disconnectedbehavior among the widows in Kaduna metropolis. Hawton et al. [26] suggested that practices should target people at risk of social disconnectedness, as individuals need to be identified early with interventions before deterioration of their health or quality of life occurs.

\section{METHODS}

\section{Research Design}

The research is a quasi-experimental study involving two-group pre-test/posttest design $[27,28]$. The design is helpful as it enable the researcher to select sample on purpose for the study, and help to assess the effectiveness of a given intervention by comparing before and after outcome of participants [29]. Usually, if the intervention is effective, participants' outcome scores will improve compared to baseline, but scores will remain constant if the intervention has no effect [30].

\section{Participants}

The population of the study includes all widows in Kaduna metropolis who show symptoms of Social disconnectedness. Although, there are many widows in Kaduna state, there is however, no documented or published report about their exact number by local authorities. They however, comprised a good proportion of all women. A 2015 world report estimate puts the population in Nigeria at over two million, 2,145,605 [1]. VanVoohis and Morgan [31], and De Winter [32] suggested that using small sample size can help the researcher to give adequate attention to the subjects and it can eliminate rowdiness and possibility of attrition. The following shows the sample size of the study and the sample recruitment procedure: Out of the two hundred and three widows accessed, one hundred and twenty-eight widows agreed to participate in the study (Figure 1). They agreed to participate in the study in order to resolve their social disconnectedness behaviour. All the volunteers were gotten via notices placed at the gate to the church building, sharing of handbills, and through one-on-one

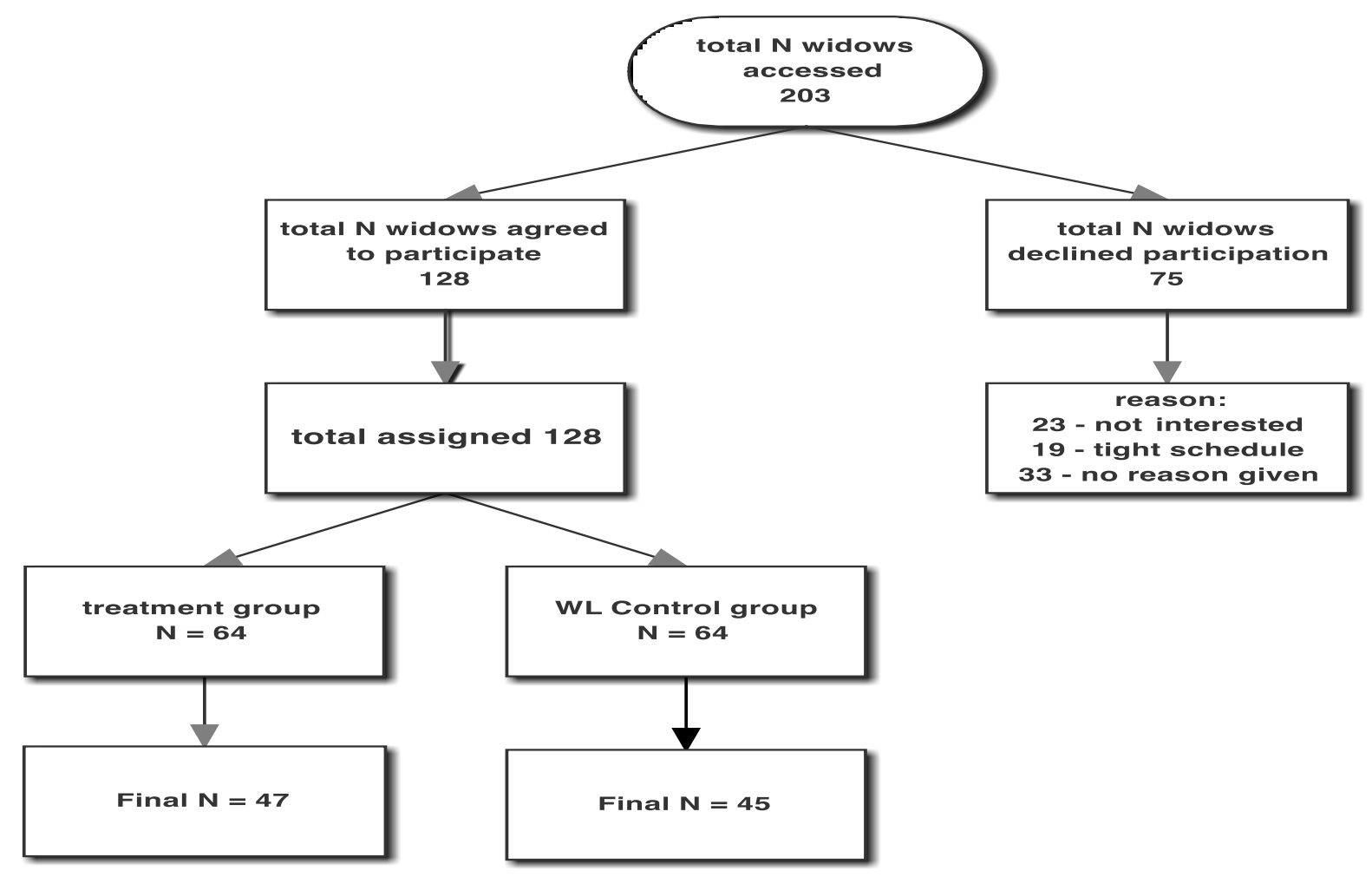

Figure 1. Sample size of the study. $\mathrm{N}=$ the number of the the widows 
contact at the widows meeting. Several researchers $[27,28,33,34]$ used similar strategy for recruiting volunteers for insomnia research. It is a recommended recruitment technique [35]. The 128 volunteers were randomly assigned into two groups of 64 each. After eight weeks, 17 [26.56\%] and 19 [29.69\%] participants from the treatment group and the control group respectively withdrew from the study.

\section{Ethical Consideration}

Participation in this research was voluntary. Only widows identified with the social disconnectedness and have agreed to participate after signing a consent form, took part in the study. The consent form as attached to the scale reads;

The essence of the study has been explained to me, and I have been given the opportunity to ask questions about this research. I understand the aims, duration of the intervention and have agreed to participate. I was also assured of confidentiality of any information I gave. I understand that my participation is voluntary, so I can withdraw from the study at any time.At the end of the study, the waitlist control group was introduced to the treatment and was given handout on how to use it at home.

\section{Treatment Credibility}

Two items from the Treatment Evaluation Questionnaire [36] were used to assess treatment credibility, and these items were completed at post treatment. These items were chosen because they appeared less likely to beaffected by treatment success or failure, though it remained possible that treatment response biased these findings. Participants reported whether they felt the treatment was logical and reasonable and whether they would recommend the intervention to a friend with a similar problem. The items were measured on a Likert scale ranging from 0 (strongly disagree) to 5 (not sure) to 10 (strongly agree).

\section{Measure}

The social disconnectedness questionnaire (SDQ) developed by Russell [37] was used to assess social disconnectedness behaviour among participants during pretreatment and post treatment phases. The Social isolation questionnaire includes 20 questions used to assess how lonely the respondent feels. Each question begins with the statement "How often do you feel" followed by a positive or negative description of social interactions with others. The respondent is asked to indicate the frequency he/she feels that way (never $=1$, rarely $=2$, sometimes $=3$, always $=4$ ) for each question. The instrument is suitable for respondents between the ages of 18 and above. Items $1,5,6,9,10,15,16,19$, and 20 were scored in reversed. All scores were summed together with higher scores indicating greater degrees of isolation or disconnectedness [37].

Generally, the instrument was divided into sections. The first section was made up of demographic characteristics of the respondents (age, personal income, years of widowhood, number of children, and source of financial assistance), while the second section consists of statements used to assess the dependent variable (social disconnectedness). The social disconnectedness questionnaire produced a satisfactory reliability index and consistency and it is the most commonly used instrument to assess social isolation behaviour. The scale has internal consistency of 0.89 to 0.94 and test retest of 0.73 [37]. It has been used successfully in several countries with different cultures [38-40].

\section{Intervention}

The data collection procedure was discussed in three phases; the first is pretreatment phase, then second; treatment phase, and third; post-treatment phase (Table 1).

\section{Pretreatment Phase (week 1)}

During week 1, the researcher introduced himself to the volunteered research participants. The participants received briefing on the essence of the study and filled consent form approving their voluntary participation in the study. We (researcher and 2 assistants) administered self-monitoring questionnaire, whichwe used to measure widows level of social disconnectedness. We used the datacollected at this stage to serve as the pretest data and bases for inclusion to the study. Participants were directed on how to fill the instruments and after that, advance arrangements were made concerning further meetings.

\section{Treatment Phase (week 2-7)}

The treatment was done in-group, so all the 
Table 1. Brief explanation of self-monitoring intervention

\begin{tabular}{|c|c|c|}
\hline Session & Self-Monitoring Technique (Group B) & Description \\
\hline Session one & Introduction and Pretest/intake & $\begin{array}{l}\text { This stage involves familiarization, intake and pretest } \\
\text { administration of outcome instrument and SDQ. }\end{array}$ \\
\hline Session two & Identifying target behavior & $\begin{array}{l}\text { Participants worked with the investigator to identify } \\
\text { target behaviour that needs to be addressed }\end{array}$ \\
\hline Session three & Defining the target behavior & $\begin{array}{l}\text { The behaviour identified were defined, and analysed } \\
\text { so as to come up with a better behaviour replacement }\end{array}$ \\
\hline Session four & Developing replacement behavior & $\begin{array}{c}\text { The investigator helped the participants to develop } \\
\text { alternative behaviour that could counter withdrawal } \\
\text { symptomatology }\end{array}$ \\
\hline Session five & $\begin{array}{c}\text { Teaching subjects to self-monitor } \\
\text { behaviour }\end{array}$ & $\begin{array}{l}\text { After helping participants develop alternative } \\
\text { behaviour, they learned how to implement such } \\
\text { behaviour to regain lost behaviour standard }\end{array}$ \\
\hline Session six & $\begin{array}{c}\text { Monitoring progress and reviewing } \\
\text { strategies }\end{array}$ & $\begin{array}{c}\text { Strategies were reviewed while monitoring progress } \\
\text { of the intervention. SDQ was administered to } \\
\text { monitor progress }\end{array}$ \\
\hline $\begin{array}{l}\text { Session } \\
\text { seven }\end{array}$ & $\begin{array}{c}\text { Monitoring progress and reviewing } \\
\text { strategies }\end{array}$ & Continue monitoring progress \\
\hline Session eight & posttest/termination & $\begin{array}{l}\text { Participants filled the SDQ for the last time to access } \\
\text { the effects of intervention. Contact terminates and } \\
\text { participants were told to keep up good behaviour to } \\
\text { avoid relapse }\end{array}$ \\
\hline
\end{tabular}

$\mathrm{SDQ}=$ social disconnectedness questionnaire

participants in the experimental group received selfmonitoring intervention from week 2-7. Ten o'clock every Saturday morning was scheduled as the meeting time and the intervention took 58 minutes per session. The self-monitoring techniques used by Harrri et al. [41]; Jolivette and Ramsey [42]; and Carr and Punzo [43] was used for the study with some modification to suit the need of the problem under investigation. Other researchers have used the techniques and procedures and they have shown to be effective in reducing behaviour problems, but there appears to be a dearth of researches using the techniques in treating social disconnectedness among widows.

\section{Post-treatment Phase (week 8)}

At this phase, posttest using SDQ was administered. The essence was to compare with pretest outcome of both group and to examine group differences that have occurred over the course of the treatment. The rate of attrition among the study participants was $26.5 \%$ and $29.7 \%$ for experimental and waitlist control group respectively. One reason for this rate of attrition was the fact that some of the participants actually do come from far distances to the treatment venue. Before termination, the participants were informed on what to do when there is a relapse. Lastly, the participants were made to understand that longitudinal datahad shown that treatment gains achieved are extremely durable with time,they aremost often maintained or improvedover time, so relapse rates will be small so far they continue a good habit (that is, abstaining from behaviour that leads to and perpetuate the condition). Usually in experiment like this, the untreated waitlist control group needs help alsoafter the study. Thus, for ethical reason, widows in the waitlist control group were given the treatment handout explaining the systematic implementation of the treatment. The selfhelp method in experimental research has been shown toproduce some durable benefits.

\section{Statistical Analysis}

The data collected were statistically analysed with the aid of a computer software: JMP ver. 13.2. The study used ANCOVA to test for treatment effects. ANCOVA is suitable when two or more groups are subjected to pre-test and post-test while the pre-test is treated as a covariate to 'control' for pre-existing differences between the groups. However, prior to testing the treatment effects, a test of assumption of homogeneity of regression slope was carried out (see Figure 1). A 
0.05 criterion of statistical significance was used in testing the treatment effect.

\section{RESULTS}

There is a significant difference between treatment and control group in term of educational attainment $\left(\chi^{2}=12.805, p<0.01\right)$ (Table 2). The outcome showed that $19 \%$ of the participants in the treatment group had no formal education, unlike control group with only $4.4 \%$. Almost $49 \%$ of the participants in the control group had only primary education compared to $38 \%$ in the treatment group. In addition, almost $32 \%$ in the treatment had secondary education when compared to a higher $42 \%$ in the control group. Only 5 participants representing $10.6 \%$ of the total sample in the treatment group attained tertiary level of education compared to 2 participants representing $4.4 \%$ in the control group.

Regarding family size, as per number of children, analysis showed that $25.5 \%$ of the participants in treatment groupreported having 1-3 children compared to $11 \%$ in the control group. Over $36 \%$ in the treatment group have 4-6 kids compared to $73 \%$ in the control group. There were also $38 \%$ having 7 and above number of children in the treatment group compared to $15.6 \%$ in the control group. Generally, there is no significant difference in number of children between treatment and control group, $\chi^{2}=6.570, p=$ 0.087 . No significant difference rate of employment between participants in the treated and control group, $\chi^{2}=0.005, p=0.943$.

The mean response and standard errors of participants' social disconnectedness before and after the self-monitoring intervention are given in Table 3. Mean pre self-monitoring intervention of social disconnectedness among treatment group was 52.914 $\pm 1.064 ; 95 \mathrm{CI}=50.799-55.030$, but after intervention, mean social disconnectedness reduced to $32.256 \pm$ $0.905 ; 95 \mathrm{CI}=30.457-34.055$. The outcome showed a $39 \%$ remission in social disconnectedness behaviour among the treated patient. Waitlist (WL) control group on the other hand had a mean social disconnectedness

Table 2. A comparative descriptive statistics of the respondents by group

\begin{tabular}{|c|c|c|c|c|c|c|c|}
\hline \multirow[t]{2}{*}{ Group } & \multirow{2}{*}{$\frac{\text { Description }}{\text { Education }}$} & \multicolumn{4}{|c|}{ Levels } & \multicolumn{2}{|c|}{ Statistic } \\
\hline & & $\begin{array}{l}\text { No formal } \\
\text { Education }\end{array}$ & $\begin{array}{c}\text { Primary } \\
\text { Education }\end{array}$ & $\begin{array}{l}\text { Secondary } \\
\text { Education }\end{array}$ & $\begin{array}{c}\text { Tertiary } \\
\text { Education }\end{array}$ & $\mathrm{Chi}^{2}$ & $p$ value \\
\hline 1 & & $9(19.1 \%)$ & $18(38.3 \%)$ & $15(31.9 \%)$ & $5(10.6 \%)$ & 12.805 & 0.002 \\
\hline 2 & & $2(4.4 \%)$ & $22(48.9 \%)$ & $19(42.2 \%)$ & $2[4.4 \%]$ & & \\
\hline & $\begin{array}{l}\text { Number of } \\
\text { Children }\end{array}$ & $1-3$ & $4-6$ & $7+$ & & & \\
\hline 1 & & $12(25.5 \%)$ & $17(36.2 \%)$ & $18(38.3 \%)$ & & 6.570 & 0.087 \\
\hline 2 & & $5(11.1 \%)$ & $33(73.3 \%)$ & $7(15.6 \%)$ & & & \\
\hline & $\begin{array}{l}\text { Employment } \\
\text { status }\end{array}$ & Employed & Unemployed & & & & \\
\hline 1 & & $16(34.0 \%)$ & $31(66.0 \%)$ & & & 0.005 & 0.943 \\
\hline 2 & & $15(33.3 \%)$ & $30(66.7 \%)$ & & & & \\
\hline
\end{tabular}

$1=$ Treatment Group $(\mathrm{n}=47), 2=$ Waitlist $(\mathrm{WL})$ control group $(\mathrm{n}=45)$

Table 3. Pre and post mean response of treatment group and WL control group

\begin{tabular}{llrrrr}
\hline Level & \multicolumn{1}{c}{ Group } & Least Sq Mean & Std Error & Lower 95\% & Upper 95\% \\
\hline Pre-SD & Treatment Group & 52.914 & 1.064 & 50.799 & 55.030 \\
& WL Control Group & 54.266 & 1.088 & 52.104 & 56.428 \\
\multirow{2}{*}{ Post-SD } & Treatment Group & 32.256 & 0.905 & 30.457 & 34.055 \\
& WL Control Group & 51.210 & 0.930 & 49.362 & 53.059
\end{tabular}

Treatment Group $(\mathrm{n}=47)$, Waitlist $(\mathrm{WL})$ control group $(\mathrm{n}=45)$ 


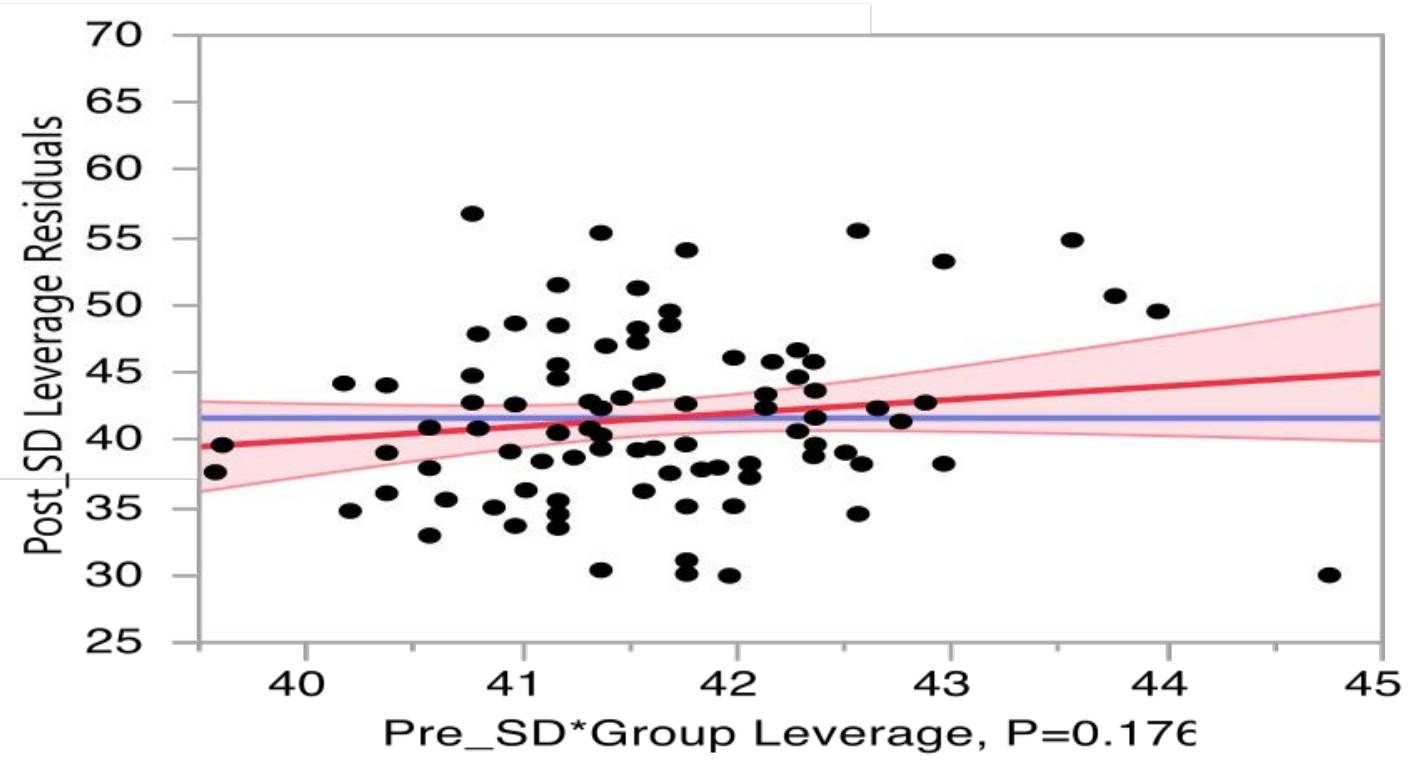

Figure 2. Leverage plot for pre_SD* group testing the homogeneity of regression slope assumption. SD = social disconnectedness.

of $54.266 \pm 1.088 ; 95 \mathrm{CI}=52.104-56.428$ at pre intervention stage, but at the end of the study, WL control group mean response reduced to $51.210 \pm$ $0.930 ; 95 \mathrm{CI}=49.362-53.059$, implying a remission of only $5.63 \%$ after eight weeks.

Figure 2 showes the analysis of covariance (ANCOVA) assumption test that requires that the relationship between the covariate and dependent variable for each of the groups is the same. Usually, similar slopes on the regression line for each group indicate this. Unequal slopes would indicate that there is an interaction between the covariate and the treatment. If there is an interaction then the results of ANCOVA could be misleading [44, 45]. In this study, the interaction is not significant, $\mathrm{F}(1,88)=1.854, p$ $=0.1768$, thus supporting the appropriateness of ANCOVA.

Analysis of covariance, which was employed to determine the effects of group on social disconnectedness is shown in Table 4. Outcome showed that generally, there is a significant effect of group $\mathrm{F}(2,89)=111.1635, p<0.0001 ; \mathrm{RMSE}=$ 6.189 , implying that the two groups (treatment and WL control group) responded significantly different due to self-monitoring intervention. The overall model was found to explain $71.4 \%$ variance.

The expanded estimates nominal factors expanded to all levels are shown in Table 5. It showed that pretreatment outcome did not significantly influence the later outcome of the study, $\beta=0.1399[95 \% \mathrm{CI}=$ $0.039-0.318], \mathrm{t}=1.56, p=0.123$. The intervention was significantly effective for the participants in the treatment group, $\beta=-9.521[95 \% \mathrm{CI}=-10.815-$ 8.227], $\mathrm{t}=-14.62, \mathrm{p}<0.0001$ compared to those in the WL control group, $\beta=9.521$ [95\%CI $=8.227$ $10.815], \mathrm{t}=14.62, p<0.0001$. Participants in the treatment group had higher reduction in their social disconnectedness behaviour than did those in the WL control group.

Table 4. Analysis of variance showing model effects for groups

\begin{tabular}{lccccc}
\hline Source & DF & Sum of Squares & Mean Square & F Ratio & Prob $>$ F \\
\hline Model & 2 & 8596.436 & 4298.22 & 111.1635 & $<\mathbf{0 . 0 0 0 1}$ \\
Error & 89 & 3441.249 & 38.67 & & \\
C. Total & 91 & 12037.685 & & &
\end{tabular}

Summary of Fit: RSquare $=0.714$; RSquare Adj = 0.707; Root Mean Square Error =6.218; Mean of Response $=$ 41.619; $\mathrm{N}=92$ 
Table 5. Expanded estimates nominal factors expanded to all levels [treatment vs WL control]

\begin{tabular}{lcccccc}
\hline Term & Estimate & Std Error & $\mathbf{t}$ Ratio & Prob $>|\mathbf{t}|$ & Lower 95\% & Upper 95\% \\
\hline Intercept & 34.337 & 4.855 & 7.07 & $<\mathbf{0 . 0 0 0 1}$ & 24.689 & 43.984 \\
Pre_SD & 0.1399 & 0.090 & 1.56 & 0.1230 & -0.039 & 0.318 \\
Treatment Group & -9.521 & 0.651 & -14.62 & $<\mathbf{0 . 0 0 0 1}$ & -10.815 & -8.227 \\
WL Control Group & 9.521 & 0.651 & 14.62 & $<\mathbf{0 . 0 0 0 1}$ & 8.227 & 10.815 \\
\hline
\end{tabular}

$\mathrm{WL}=$ Waitlist

\section{DISCUSSION}

The basic essence of the study was to examine the effectiveness of self-monitoring intervention in reducing problem behaviour of social disconnectedness among widows. The result suggests that self-monitoring intervention is an effective strategy to help reduce social disconnectedness behaviour among widows in Nigeria. In this study, SM reduced SD by $39 \%$ in eight weeks. This corroborate findings on multiple baseline study across participants by Craanen [46], which investigates the effect of a self-monitoring treatment intervention on academic productivity component behaviors among students with Autism Spectrum Disorder. Results show all participants achieved marked improvements in their academic productivity composite scores from baseline to intervention to the maintenance phase. Furthermore, previous finding by Cassidy [47] using selfmonitoring to improve the academic performance of a male student with attention deficit hyperactivity disorder (ADHD) shows that the student improved grade average in all five classes. The improvement was classified as from $0 \%$ of the time to $50 \%$ of the time, showing the helpfulness of self-monitoring intervention. In another multiple-baseline-acrosssubjects design study, Hughes et al. [48] used a multiple-baseline-across-participants design to examine the effects of self-monitoring on selected social behaviors of students with mental retardation. Result shows occurrences of self-monitoring were associated with improvement in target behaviors across participants. In another similar finding, Car et al. [49] reported that volunteerism successfully attenuate loneliness among widows to the extent that loneliness among widows was found to be similar to those of continuously married individuals. A previous study by Constantino et al. [50] on bereavement using group intervention showed that resulted to statistically significant changes in psychological wellbeing. There was a significant increase in social adjustment among widows survivors' of suicide. In line with outcome of this intervention, Onrust et al. [51] in their study on effects of visiting service for older widowed individuals found that visiting service improved the socially lonely, physically ill, and low educated widows than in experimental group than in the control group.

\section{Limitations}

This present study has several limitations, though. Firstly, the study relied on self-reported measures of social disconnectedness instead of objective measure. Secondly, other physical and mental health problems not included or taken care of in this study may create asymmetries in widows' social relationship and limit their abilities and desires to develop and maintain healthy social relationships. Secondly, the study only questioned the participant's level of education, number of children and employment status. Other sociodemographic features like the number of siblings, the degree of closeness with siblings, the existence of close friends, the time of loss of spouse, the number of years of widowhood, may all related to losing reaction. The fact that these variables were not looked at is a limitation of this study. Thirdly, using individual rather than group intervention may produce better outcome as each participants would be given adequate attention. Based on these limitations, we therefore state categorically that causal connections implied by the findings of this study should be interpreted and taken with caution. It is hope that further research will refine these concepts, address the study limitations to reveal causal mechanisms, and help researchers and 
policymakers to better understand the health risks of social disconnectedness among widows and developing behavioural methods to help widows to take back their lives.

\section{CONCLUSION}

The present research is an early step forward towardsprobing the relative effects of self-monitoring intervention on social disconnectedness among widows. In this study, we found out that the treatment successfully reduced social disconnectedness among widows in Kaduna state, Nigeria by $39 \%$ after eight weeks of contact compared to the $5.6 \%$ for the control. The study outcome may advance the area of grieve support and aid a healthy adaptation to widowhood.

\section{Conflict of interest}

The authors disclosed no conflict of interest during the preparation or publication of this manuscript.

\section{Financing}

The authors disclosed that they did not receive any grant during conduction or writing of this study.

\section{REFERENCES}

[1] The Loomba Foundation. The Global Widows Report 2015. A Global Overview of Deprivation Faced by Widows and Their Children. London. Loomba House. 2015.

[2] The caribbean current. Plight of widows in the global arena. 2012; Retrieved feb. 10, 2017 via https://thecaribbeancurrent.com/plight-of-widows-in-the-globalarena/

[3] Vasa RA, Pine DS. Anxiety disorders. In Child and adolescent psychopathology: Theoretical and clinical implications. 78-112. New York, NY, US: Routledge/Taylor Francis Group. 2006.

[4] Kano R, Kondo N. Social Withdrawal of Young People, Psychosocial Background, Pathology and Treatment Aid. Iwasaki Gakujyutu Shuppan, Tokyo. 2000.

[5] Geller J, Janson P, McGovern E, Valdini A. Loneliness as a predictor of hospital emergency department use. J Fam Pract 1999;48:801-4.

[6] Victor CR, Scambler SJ, Shah S, Cook DG, Harris T, Rink E, et al. Has loneliness amongst older people increased? An investigation into variations between cohorts. Ageing Soc 2002;22:585-97.

[7] Alpass FM, Neville S. Loneliness, health and depression in older males. Aging Ment Health 2003;7:212-6.
[8] Cohen-Mansfield J, Parpura-Gill A. Loneliness in older persons: a theoretical model and empirical findings. Int Psychogeriatr 2007;21:410-29.

[9] Rubin K, Bukowski W, Parker J. Peer interactions, relationships, and groups. In W. Damon, \& N. Eisenberg (Eds.) Handbook of child psychology: Social, Emotional, and Personality Development 6th ed.,. New York: Wiley. 2006.

[10] Hymel S, Woody E, Bowker A. Social withdrawal in childhood: Considering the child's perspective. In KH Rubin, JB Asendorpf (Eds.) Social withdrawal, inhibition, \& shyness in childhood Hillsdale, NJ: Erlbaum. 1993. pp. 237-62.

[11] Megan CJ, Galit N, Douglas AK. Leisure patterns and health among recently widowed adults. Act Adapt Aging 2008;32:1939.

[12] Agena T. The Impact of the Nigerian civil war on Tiv soldiers of central Nigeria. In Armstrong MA (ed.) The Nigerian civil war: Forty years after. Makurdi, Aboki Publishers. 2008.

[13] Alubo O. Ethnic conflicts and citizenship crisis in the central region. Ibadan, Eddy Asae Nigerian Press. 2006.

[14] Hembe GN, Tarka JS. The dilemma of ethnic minority politics in Nigeria. Makurdi, Aboki Publishers. 2003.

[15] Suberu R. Ethnic minority conflicts and government in Nigeria, Ibadan, Spectrum Books. 1996.

[16] Anifowose R. Violence and politics in Nigeria: The Tiv and Yoruba experience. New York, Nob Publishers International. 1982.

[17] Akogun K, Obi P, Sowole J. Police HQ Bombing: Nine victims handed over to police. This Day Newspaper, Sunday, June 19, 2011.

[18] Onojovwo D. Six killed, 22 injured as bombers hit media houses. National Mirror Newspaper, Friday, April 27, 2012.

[19] Alli Y. Boko Haram strikes again as Kaduna count losses. The Nation Newspaper, Tuesday, April, 10, 2012.

[20] Adamu LD. 2 Profs, 17 others Killed in BUK attack. Daily Trust Newspaper, Monday, April, 30, 2012.

[21] Eweluka UU. Post-colonialism, gender, customary injustice: Widows in African societies. Hum Rights Q 2002;24:424-86.

[22] Afolayan GE. Widowhood practices and the rights of women. The case of South-Western Nigeria. Erasmus: International Institute of Social Studies. 2011.

[23] Jakobsson U, Hallberg IR. Loneliness, fear, and quality of life among elderly in Sweden: a gender perspective. Ageing Clin Exp Res 2005;17:494-501.

[24] Findley RA. Interventions to reduce social isolation amongst older people: where is the evidence? Aging Soc 2003;23:647-58. [25] Sander R. Preventing social isolation and loneliness among older people: a systematic review of health promotion activities. Nurs Older People 2005;17:40.

[26] Hawton A, Green C, Dickens A, Richards S. Taylor R, Edwards R, et al. The impact of social isolation on the health status and health-related quality of life of older people. Qual Life Res 2011;20:57-67.

[27] Victor M, Adeniyi, EF. Cognitive behaviour techniques for primary insomnia: A non-randomized study among university students. Int J Med Sci Appl Biosci 2017;2;137-52.

[28] Victor M, Balarabe M, Mohammed IA, Umaru Y. Cognitive behaviour and relaxation techniques: a comparative study among 
university students in Nigeria with primary insomnia. Arch Curr Res Int 2018;13;1-11.

[29] Mark MM, Gamble C. Experiments, quasi-experiments and ethics. In DM. Mertens PE. Ginsberg eds, Handbook of social research ethics. Thousand Oaks, CA: Sage. 2009. pp. 198-213.

[30] Max, M, Lynn, J. Interactive textbook on clinical symptom research. United States. Department of Health and Human Services. 2003.

[31] VanVoohis CR, Morgan, BL. Understanding power and rules of thumb for determining sample sizes. Tutor Quant Methods Psychol 2007;3:43-50.

[32] De Winter JFC. Using student's t test with extremely small sample size. Practical Assessment, Research and Evaluation, 2015; 18 (10). Retrieved January 15, 2016 from http://pareonline.net/getvn.asp?v=18\&n=10.

[33] Carney CE, Harris AL, Moss TG, Edinger JD. Distinguishing rumination from worry in clinical insomnia. Behav Res Ther 2010;48:540-6.

[34] Vitiello MV, Rybarczyk B, Von Korff M, Stepanski EJ. Cognitive behavioral therapy for insomnia improves sleep and decreases pain in older adults with co-morbid insomnia and osteoarthritis. J Clin Sleep Med 2009;5:355-62.

[35] Agency for Healthcare Research and Quality. Participant Recruitment for 2012. Available:http://healthit.ahrq.gov/ahrqfundedprojects/emerginglessons/participantrecruitmentresearch.

[36] Borkovec TD, Nau SD. Credibility of analogue therapy rationales. J Behav Ther Exp Psychiatr 1972;3:257-60.

[37] Russell D. The UCLA Loneliness Scale (Version 3): reliability, validity, and factor structure. J Pers Assess 1996;66:20-40.

[38] Doane LD, Adam EK. Loneliness and cortisol: momentary, day to day, and trait associations. Psychoneuroendocrinology 2010;35:430-41.

[39] Pressman SD, Cohen S, Miller GE, Barkin A, Rabin BS, Treanor JJ. Loneliness, social network size and immune response to influenza vaccination in college freshmen. Health Psychol 2005;24:297-306.

[40] Seeman TE. Health promoting effects of friends and family on health outcomes in older adults. Am J Health Promot
2000;14:362-70.

[41] Harris KR, Graham S, Reid R, McElroy K, Hamby RS. Selfmonitoring of attention versus self-monitoring of performance: replication and cross-task comparison studies. Learn Disabil Q 1994; 17:121-39.

[42] Jolivette K, Ramsey M. Students with emotional and behavioral disorders can manage their own behavior. Teach Except Child 2006;39:14-21.

[43] Carr S, Punzo R. The effects of self-monitoring of academic accuracy and productivity in the performance of students with behavioral disorder. Behav Disord 1993;18:241-50.

[44] Stevens J. Applied multivariate statistics for the social sciences (3rd edn). Mahwah, NJ: Lawrence Erlbaum. 1996.

[45] Tabachnick BG, Fidell LS. Using multivariate statistics. 6th ed., Boston: Pearson Education. 2013.

[46] Craanen PM. The Effect of a Self-Monitoring Treatment Intervention Package on the Academic Productivity Behavior of Three High Schools Students with Autism Spectrum Disorder. A dissertation submitted in partial fulfillment of the requirements for the degree of Doctor of Education in the School of Teaching, Learning and Leadership in the College of Education at the University of Central Florida Orlando, Florida. 2013.

[47] Cassidy B. Self-monitoring to Improve Academic Success for a High School Student Identified with Attention Deficit Hyperactivity Disorder. Running Head; College of Education and Human Development University of Southern Maine. 2010.

[48] Hughes C, Agran M, Copeland SR, Wehmeyer ML, Rodi MS, Presley JA. Using Self-Monitoring to Improve Performance in General Education. 2002.

[49] Carr DC, Kail BL, Matz-Costa C, Shavit YZ. Does becoming a volunteer attenuates loneliness among recently widowed older adults? J Gerontol B Psychol Sci Soc Sci 2018;73:501-10.

[50] Constantino RE, Sekula LK, Rubinstein EN. Group Intervention for widowed survivors of suicide. Suicide LifeThreat Behav 2001;31:428-41.

[51] Onrust AS, Willemse G, Van den Bout J, Cuijpers P. Effects of visiting service for older widowed individuals: a randomized clinical trial. Death Stud 2010;34:777-803. 